\title{
Vegan YouTubers Performing Ethical Beliefs
}

\author{
Kim Harding * and Abby Day * \\ Department of Sociology, Goldsmiths, University of London, London SE14 6NW, UK \\ * Correspondence: khard001@gold.ac.uk (K.H.); abby.day@gold.ac.uk (A.D.)
}

check for updates

Citation: Harding, Kim, and Abby Day. 2021. Vegan YouTubers Performing Ethical Beliefs. Religions 12: 7. https://dx.doi.org/ $10.3390 /$ rel12010007

Received: 22 November 2020 Accepted: 19 December 2020 Published: 23 December 2020

Publisher's Note: MDPI stays neutral with regard to jurisdictional claims in published maps and institutional affiliations.

Copyright: () 2020 by the authors. Licensee MDPI, Basel, Switzerland. This article is an open access article distributed under the terms and conditions of the Creative Commons Attribution (CC BY) license (https: / / creativecommons.org/ licenses/by/4.0/).

\begin{abstract}
In Great Britain, "religion or belief" is one of nine "protected characteristics" under the Equality Act 2010, which protects citizens from discrimination in the workplace and in wider society. This paper begins with a discussion about a 2020 ruling, "Jordi Casamitjana vs. LACS", which concluded that ethical vegans are entitled to similar legal protections in British workplaces as those who hold philosophical religious beliefs. While not all vegans hold a philosophical belief to the same extent as Casamitjana, the ruling is significant and will be of interest to scholars investigating non-religious ethical beliefs. To explore this, we have analysed a sample of YouTube videos on the theme of "my vegan story", showing how vloggers circulate narratives about ethical veganism and the process of their conversion to vegan beliefs and practices. The story format can be understood as what Abby Day has described as a performative "belief narrative", offering a greater opportunity to understand research participants' beliefs and related identities than, for example, findings from a closed-question survey. We suggest that through performative acts, YouTubers create "ethical beliefs" through the social, mediatised, transformative, performative and relational practice of their digital content. In doing so, we incorporate a digital perspective to enrich academic discussions of non-religious beliefs.
\end{abstract}

Keywords: veganism; ethical belief; philosophical belief; non-religion; YouTube; mediatisation; secularisation; performativity; digital religion

\section{Introduction}

In January 2020, an employment tribunal in England ruled that ethical veganism is a philosophical belief that is protected by law against discrimination. Jordi Casamitjana, who was 55 at the time of the ruling, had previously worked as head of policy and research for animal welfare charity the League Against Cruel Sports (2020). After discovering that the charity's pension funds were invested in pharmaceutical firms that test products on animals, Casamitjana wrote to his work colleagues to share that information and express his disapproval: he was subsequently dismissed by LACS. Casamitjana took a case of unfair dismissal to an employment tribunal where he reached a settlement with LACS, which issued a statement on its website accepting that Casamitjana "did nothing wrong" by communicating his concerns about pension arrangements to his colleagues (League Against Cruel Sports 2020).

Casamitjana vs. LACS is not the first such ruling on a non-religious belief. In November 2009, a UK judge ruled in Grainger PLC vs. T Nicholson that an employee's beliefs about human generated climate change were as worthy of protection under the 2010 Equality Act as a religious or philosophical belief ${ }^{1}$. The criteria for determining a philosophical belief, in the words of the 2010 Equality Act, are that "it must be genuinely held; be a belief and not an opinion or viewpoint based on the present state of information available; be a belief as to a weighty and substantial aspect of human life and behaviour; attain a certain

1 For discussion of this and other legal cases involving religion, see Abby Day (2020): Sociology of Religion, Overview and Analysis of Contemporary Religion. London: Routledge. 
level of cogency, seriousness, cohesion and importance; and be worthy of respect in a democratic society, compatible with human dignity and not conflict with the fundamental rights of others" (Legislation.gov.uk 2010). The Casamitjana vs. LACS ruling does not imply that all vegans have a philosophical belief. It specifically applies to Casamitjana's deeply held beliefs, which go beyond eating a plant-based diet: for example, he refuses to eat figs because of their symbiotic relationship to a particular wasp (Doward 2019). The ruling is, however, significant and will be of interest to scholars researching non-religious beliefs. As Blanes and Oustinova-Stjepanovic $(2015$, p. 5) note, while the term non-religion has "gained epistemological ground", uncertainty remains about how the concept can act as an umbrella term and describe "specific empirical phenomena that might not be easily subsumed under one category". While we cannot make a claim here to clearly define non-religious beliefs, we use the 2010 Equality Act and its application in Casamitjana vs. LACS as a starting point for analysing a specific empirical phenomenon and demonstrating how it can act as an umbrella term for understanding a facet of non-religious ethical beliefs (while acknowledging the instability of non-religion as a category) to show how ethical-vegan beliefs on YouTube demonstrate the criteria of cogency, seriousness, cohesion and importance set out by the tribunal to qualify as a (non-religious) belief. In doing so, we also suggest a path for non-religion and digital religion researchers alike to develop further empirical work concerning how other forms of ethical beliefs are mediatised. In this article, we will discuss ethical beliefs about veganism by analysing a sample of 15 YouTube videos on the theme of "my vegan story". In considering how YouTubers talk about veganism using this narrative format, we will show how philosophical, ethical beliefs are performatively formed in part by watching other YouTubers, as well as user-generated content about veganism on other social media platforms. The way YouTubers talk about self-education and "making the connection" is crucial to how these vloggers become vegan; thus, the formation of an ethical belief is shown to be a mediatised, transformative, performative and relational practice. This supports the view that emotional forms of belief are significant evidence of non-religious beliefs replacing institutional and civil forms of religion in Euro-American contexts (Day 2016, p. 67). Assessing ethical living practices online brings a digital religion perspective to build on the work of Day (2011), which takes belief to be produced by belonging; it also responds to Lövheim's (Lövheim 2016, p. 107) call for Day's work to be developed using the dimension of mediatization-particularly the nature of performativity and sociality when relationships are mediated digitally.

\section{Capturing the Non-Religion Category}

Lee has acknowledged that non-religion may be "a limited category" and is "essentially arbitrary-that is to say, it is historical and contingent", conceding that non-religion may be something of a placeholder term, albeit one that can facilitate future empirical work (Lee 2015, p. 194). It is not a perfect term, she has argued elsewhere (Lee 2012, p. 134); it is pragmatic and relative to religion "because religion has dominated relevant areas of thought for some centuries and continues to do so at the point at which non-religious scholars enter the debate". For scholars of non-religion, however, employing terms such as non-religion and unbelief in research raises the methodological dilemma of "investigating one phenomenon through the lens of another" (Cheruvallil-Contractor et al. 2013, p. 177). In her study of self-defining atheists, Trzebiatowska $(2018$, p. 3) notes that it remains a challenge to research a social category rather than a group. This is the case for scholars investigating the non-religion category, which not only needs to be approached critically, but also requires engagement with participants to ask how they relate to the category, so that they can self-define in ways that are salient to them. Cotter's study of Scottish university students, in reference to Day (2009, p. 90), engages with non-religion "as it is lived, experienced and expressed and seeks to avoid imposing the researcher's preconceived category onto informants [ ... ] How an individual claims to understand 'non-religion' will depend upon their understanding of 'religion'" (Cotter 2011, pp. 8-9, author's italics). Woodhead's (Woodhead 2016, pp. 43-44) surveys point to what she calls a "blurring of boundaries" 
in self-identification as non-religious, noting that while more and more British people are non-religious, it does not mean that they are secular. She notes: "Non-religion is not really an identity category at all, it's an artefact of pre-existing, modern survey categories [... ] And even those who can still tick the old religious boxes don't necessarily behave or believe in the way they are expected to." Thus, the empirical study of non-religious individuals requires creativity to uncover research participants' understanding of what they are actually doing when they, as do $52 \%$ of the British public (British Social Attitudes 2019, pp. 1-2), tick the new non-religious box. The method we use here follows Day's (Day 2011) formulation of the "belief narrative", incorporating seven dimensions of meaning and perspective, including content, source, practice, function, salience, time, and place.

This paper explores ethical belief and how it is performed in a digital context by considering how ethical beliefs are shaped and transmitted using social media channels, particularly YouTube. Mediatisation is employed as a theoretical framework for considering what Hepp et al. (2015, p. 314) describe as the "interplay between media, culture and society". Research into media and religion has received a significant amount of academic attention (for example, Engelke 2010; Hjarvard and Lövheim 2012). Hjarvard has developed mediatisation's relevance for the study of religion, arguing (Hjarvard 2008, p. 9) that religion has become "subsumed under the logic of the media", a concept he borrows from Altheide and Snow (1979), with processes of mediatisation elevating the media to become the primary source of religious ideas, moulding religious imagination "in accordance with the genres of popular culture". Hjarvard contends that the media "as cultural environments have taken over many of the social functions of the institutionalised religions, providing both moral and spiritual guidance and a sense of community" (Hjarvard 2008, p. 9). YouTube certainly plays this social function, with vegans on YouTube acting in a dynamic community to create and consume narratives about the formation of ethical beliefs. Moreover, Clark's (Clark 2011, p. 167) understanding of mediatisation as "the process by which collective uses of communication media [ ... ] contribute to new forms of action and interaction in the social world and give shape to how we think of humanity and our place in the world" can be extended in this paper to consider how vegan YouTubers think about their place in the world to include the lives of the animals that they choose not to consume as they formulate their ethical beliefs. Finally, Day's neo-Durkheimian suggestion that moral authority is situated in the social rather than the divine (Day 2011, p. 191) is developed in this paper to ask how the social is mediated by the logic of the digital; that is to say, how ethical beliefs are shaped and repurposed to fit the affordances of social media platforms. Investigating these ethical belief narratives adds to Day's (Day 2011, pp. 179-80) theoretical concept of the belief orientation of anthropocentricity, which situates "power and authority with people, not gods". Day's research suggests there is little difference between the two belief orientations of anthropocentricity (whereby human beings are "centric" to one's life) and theocentricity (whereby God is central to one's life) as "they share the same functions of creating a sense of belonging", thus producing a Durkheimian interpretation whereby religion "is not rooted in a belief in the supernatural but in those activities that bind people" (Day 2011, p. 172). The difference between the two orientations is where they locate the source of legitimacy: the human or divine. Thus, "belief" can be reclaimed as both a religious and a non-religious term, the main implication of which can be to "dispense with binary [ ... ] categories of belief such as 'religious' or 'secular' and focus instead on "multidimensional orientations" (Day 2011, p. 202). Attending to the ethical beliefs of YouTube content creators offers an opportunity to investigate these multidimensional orientations and to widen the scope for future digital religion scholarship so that it includes the digital belief lifeworlds of the non-religious.

\section{The Ethical Turn in People's Relationship to Food}

As noted by Lewis and Huber (2015, pp. 289-91), the ethical turn, a "mainstreaming of ethical concerns" that has taken place over the past two decades around questions of food production and consumption in wealthy nations, is driven in part by coverage of 
ethical consumerism in mainstream media. In other words, it is mediatised. Consumption practices are opportunities to make ethical choices and "make a difference" through what we buy, situating "ethical consumption, moral obligation and choice in the everyday" (Adams and Raisborough 2010, p. 256). While the choice not to eat meat and dairy, or use any products derived from animals, is an act of non-consumption, the rising popularity of veganism, in the UK and in other westernised countries, has resulted in a burgeoning market for vegan products. In 2018, the UK launched more vegan products than any nation, while the number of vegans in Great Britain (namely England, Wales and Scotland, excluding Northern Ireland) quadrupled between 2014 and 2019; by 2019, there were 600,000 vegans, or $1.16 \%$ of the population, with vegans and vegetarians looking set to make up a quarter of the British population by 2025 (The Vegan Society 2020, derived from reports by Mintel; Ipsos Mori; the Food Standards Agency; the National Centre for Social Science Research; and UK supermarket chain Sainsbury's). Significantly, British multinational grocery retailer Tesco announced in September 2020 that it was committing to increasing sales of plant-based alternatives to meat by $300 \%$ within five years (Smithers 2020).

Ethical veganism can be viewed as a moral choice that reduces the exploitation and suffering of animals (Greenebaum 2016, p. 2). Ethical veganism can also be considered as an anti-consumption practice. For example, Portwood-Stacer $(2012$, p. 96) describes moral anti-consumption as practices that are construed as moral, "in that by reducing one's demand for goods produced under objectionable conditions, one reduces one's complicity with the system or entities that perpetuate those conditions". As Manyukhina (2017, p. 596) notes, ethical consumption can be "complex and diverse in its performances and understandings". This paper seeks to understand performances of mediatised ethical belief and adds to literature about human/nonhuman animal relationships such as Beaman, who uses sea turtle rescue as a site "of action and activism [to contribute] to a deeper understanding of the contours of both religion and non-religion and their relationship to each other" (Beaman 2017, p. 9), as well as Salonen, who suggests that the research of food consumption and its ethical dimensions "transcends the boundaries between belief and practice, dogma and ethics, and religion and non-religion" (Salonen 2018, p. 12). Beaman draws in part on Ingold (2013, pp. 16-17), who asks: "Why should anyone think that social relations should be confined to individuals of the same species? [ ... ] are not these crossspecies entwinings [ ... ] just as social as are human and animal entwinings with others of their respective kinds?". In this paper, vegan YouTubers' narratives of human/non-human entanglement demonstrate how their social action is entwined with the animals that they have chosen not to consume.

\section{Method and Ethics}

The main method used for this research was "purposive sampling", whereby we located YouTube videos in which content creators tell stories about the formulation of their ethical beliefs. We did this by conducting YouTube searches using the keywords "my vegan story", "vegan story time" and "ethical vegan story". To recruit the sample for this paper, content creators were chosen because they discussed the ethical aspects of being vegan in their video; YouTubers whose vegan stories only discussed the dietary or health aspects of their veganism were not chosen for recruitment. Once a pool of potential contentcreator research participants had been generated, ethical approval for data collection was sought from our home department, (Sociology, Goldsmiths, University of London), so that potential participants could be contacted individually and asked if they would give their consent for a transcript of their YouTube video to be used in the research. Forty content creators were approached in August and September 2020. We received responses from 16 YouTubers, all of which granted their consent for a transcript of their vegan story video to be used for this paper, which relates to 15 videos. A review of the YouTube videos from the non-consenting content creators approached for the study suggests that in their vegan stories, they support the data from consenting participants, most notably the importance 
to ethical vegans of research and self-education, not only through documentaries such as Cowspiracy and Earthlings, but also through acquiring ethical vegan beliefs through content creators on YouTube and other social media channels.

The ethics of using publicly available content in internet research is a complicated and ever-changing landscape, with researchers finding themselves in a "constantly shifting conceptual terrain" as they try to meet the challenges of protecting the privacy of research participants (Markham 2012, p. 336). A challenge in online video research is gaining informed consent and maintaining the ethical principle of respecting those whose data are being used (Legewie and Nassauer 2018); thus, potential informants should know that they are being researched and then be able to give or withhold their consent for their data to be used. In conducting data collection for this article, we heeded Patterson (2018, p. 765) guiding suggestion that the "seemingly endless data points" of online spaces should not "become disassociated from the individuals who breathe life into them". All YouTubers for this study were approached using the email supplied on their YouTube page and sent an information sheet outlining the purpose of the study as: "to investigate how YouTubers communicate narratives about the ethical aspects of being vegan by analysing a sample of videos on the theme of 'my vegan story'". Potential participants were informed about the possible benefits of taking part in the research, such as contributing to an academic understanding of ethical belief as it relates to veganism and helping to add a digital culture perspective to academic discussions of non-religious belief. Content creators are anonymised throughout, although they were given the option to use their real name or channel name. As Guenther (2009, pp. 413-14) argues, naming is powerful and choosing to use names or alter names is something researchers should consider carefully when considering the anonymity, or otherwise, of participants. In Guenther's work with feminist activists in eastern Germany, many respondents "wanted to be heard [ ... ] by guaranteeing their confidentiality, I was in effect denying my respondents the right to be heard; in renaming them through the use of pseudonyms, I was denying them the basic right to be who they are". And yet, it may also be problematic to reveal the real names of some of the participants when so doing may also reveal, by association or location, the identities of those who wish to remain anonymous. In the final sample for this research, two participants asked if their YouTube usernames could be used. Other content creators are anonymised using pseudonyms and not identified in this article except by gender, country location and the story that they have already recounted in their publicly available YouTube video. Subscriber numbers-a subscriber being someone who chooses to follow a channel to stay updated with its content-for the YouTube channels in this sample range from double figures to 693,000. Videos were created between 2015 and 2020. Six creators in the sample come from the US, with three from the UK; two from Canada; two from Australia; and one each from The Netherlands, Ireland and Denmark.

Of the 15 respondents, two were men. The impact of gender lies outside the scope of this article due to the small sample size and we therefore make no claims based on that category, while noting that issues of gendered affect in the transmission of ethical belief narratives presents an interesting area for future research. This is important because social media influencers-individuals that build a reputation for their expertise and who eventually can affect the purchasing decisions of their audiences-build creation narratives of their personal lives. Financial reward for this creative labour is not always guaranteed (Duffy 2016, p. 441). Arcy (2016, p. 366) describes this labour as operating through "affective intensities", using Hochschild [1983] (2012) to draw attention to how emotion is used to add value to branded platforms. YouTube in particular, note Berryman and Kavka (2018, p. 95), places a premium on the intimate information that content creators wish to divulge. Women's self-performances in digital media has been described as a "communicative intention towards authentic self-expression" (Lövheim and Lundmark 2019, p. 23), yet this authenticity can also be framed as a pursuit of influence, with content creators engaged in a "visibility game" that is constructed around the "rules" encoded within opaque proprietary algorithms (Cotter 2019, p. 895), with vloggers sometimes engaging in "algorithmic 
gossip" to gain visibility on social media platforms that are algorithmically structured (Bishop 2019, p. 2589). Thus, "realness" and authenticity can be employed by content creators for strategic advantage (Abidin 2015; Duffy 2017). The ways in which beliefs, including ethical beliefs, are shaped to fit the affordances of social media platforms and their audiences presents a promising area for digital religion researchers.

\section{The Mediatisation of Ethical Beliefs}

The sample employs the "authentically styled", intimate YouTube "story time" format, what Day (2011) would describe as a "belief narrative", which shows content creators speaking directly to the camera and relating their journeys towards veganism. Data in the sample were coded according to three facets of belief: rational belief, felt belief (belief that is emotional, material and embodied), and performative belief- that is to say belief created through social action, as well as belief that creates social action. This analysis is informed by Day's "trinity of belief" (Day 2016, p. 61), a deliberately secularised analytic tool to help researchers understand the complexity of belief through three aspects: rationality, emotional/embodied and performative.

\subsection{Rational Belief}

We start with rational belief about ethical veganism. In all the videos in the sample, YouTubers relate how their decision to become vegan was based on evidence acquired from media sources, most notably YouTube itself. These beliefs about veganism are acquired from documentaries and films about animal agriculture and animal welfare, the details of which are shared by content creators; additionally, evidence about various aspects of veganism - such as factory farming processes, the environmental consequences of eating animal products and veganism's perceived dietary benefits-is acquired from other vegan content creators on the platform. Vegan stories are related in terms of self-education, where conducting self-guided research about food production is vital to form beliefs about the benefits of becoming vegan and to commit to the ethics of veganism. For example, an American vlogger, Sara, said that her research-gathering made her more comfortable and confident with being vegan:

"I became comfortable with the fact of being vegan, and being proud of that, and not being afraid to tell people that, and making it more of an ethical thing. So once I started finding out all this information, I made the commitment, I made the decision, and I went vegan overnight."

It is also clear, following Day (2016), that the sphere of "rational belief" is not firmly separated from emotional and embodied forms of belief. Australian content creators, Emily and Joseph, describe both their anger and their increasing rational awareness in their journey towards veganism, which began when they watched a screening of the 1991 documentary Diet For A New America while staying at an ashram in India. During this time in their lives, they were committed meat-eaters and had been somewhat apprehensive about staying on the ashram, where no meat was served at meals. On watching the documentary, their apprehension turned to annoyance after acquiring information in an experience they described as a "witnessing" - about the realities of factory farming. At the end of the screening, the audience burst into applause and Joseph recalls:

"Emily and I look at each other and went, what is this, you know, what have we just witnessed, what have we just seen? And we recall feeling angry because, we were angry that why had it taken, you know, 28 years to see and be shown this information? And also, oh no, angry that we would have to change our meat, dairy and egg-eating ways having just seen what we'd seen."

While some YouTubers describe the books they have read about veganism, such as Rory Freedman and Kim Barnouin's bestseller Skinny Bitch or Alicia Silverstone's The Kind Diet, it is the audio-visual content of YouTube, conveying harsh aspects of the animal agriculture industry, that most strongly moved them. A 2010 lecture by animal rights activist Gary Yourofsky, The Best Speech You Will Ever Hear, is cited by four YouTubers in 
the sample as an important message in the formation of a rational ethical belief. American content creator Judith describes it as a "powerful, informative" speech that "took the blinders off me [... ] I could finally see reality". Ethical belief is also acquired by YouTubers by watching feature-length documentaries such as Cowspiracy, Forks Over Knives and Earthlings, which are referenced by content creators in the sample as foundational moments in the formation of rational ethical beliefs about veganism. The graphic footage of animal exploitation and suffering in Earthlings is particularly vivid for a number of YouTubers in the sample, as described by Mila from Canada:

"I watched Earthlings and then I, oh my god, I can't eat, like, there's no way, I can't support dairy and I can't support the egg industry anymore because I just can't. [ . . . ] I just remember watching Earthlings and just crying the entire time, I don't think I've ever cried so much while watching any sort of film."

The narration of deep distress was often a feature of such descriptions. An American woman, Reece, said that she cried so much she could barely see the film: "This is what really showed me about veganism. Everything I needed to know, that in that instance, after watching it, probably after half of watching, I knew that I was going to go vegan."

While hard-hitting documentaries such as Earthlings clearly make a profound emotional impact on some YouTubers in the sample, other content creators are significantly influenced relationally in their belief formation by the narratives of other YouTubers, which demonstrate to them how veganism is lived and practised in the everyday. While this content may come from other platforms such as Instagram or Facebook, YouTube vlogs are crucial in the process of transmitting compelling accounts about the rational facts of how animals are treated to produce food, which shapes how the participants' ethical beliefs are formed. American YouTuber Reece, in relating her vegan story, says that she watched "days' worth of videos" before going vegan. For Tonia, who granted permission for her real name to be used in this paper and who makes vegan content on her channel Your Vegan Friend Tonia, the abundance of vegan videos on YouTube is the reason she started her own channel. She wanted, she said, to be "somebody who somebody possibly learned something from". Irish YouTuber Alice credits the platform for her ethical journey, stating that "I went vegan pretty much from watching YouTube videos". In watching videos about veganism, she notes that digital content that contains "knowledge, wisdom and facts [... ] science and actual facts" is a more important factor in going vegan rather than "emotional" content about animals and environmental issues. British content creator Lola, meanwhile, frames social media content about veganism as a way of life to which she aspires, leading to her acquiring ethical beliefs through self-education and research. She said that:

"Basically I found veganism through social media [ . . . I I was scrolling through my explore page, and it came up with this girl who had beautiful pictures, so I was clicking on them and reading the captions. And I saw that she mentioned she was vegan [ ... ] I started to get into watching YouTubers who were vegan, and following their journeys and watching what they ate, watching how amazing and abundant their lifestyles looked."

Education, for vegan YouTubers, can lead to a transformative "conversion" experience, with those relating their vegan stories describing the moment when, having armed themselves with the facts of animal suffering, they were able to further form their ethical beliefs about why they choose not to eat animals. This could be a rational, emotional and embodied moment, as described by Canadian vlogger Audrey. After researching the meat industry, she said that "I can't now as an educated person go back to what I was doing". Likewise, UK YouTuber Clare, after looking on the internet and trying to enrich her understanding of veganism, had a "sudden realisation" that "dairy is not intended for humans, it's intended for the baby calf".

\subsection{Emotional, Embodied Belief}

The affective aspects of these accounts brings us to another analytical frame to consider the sample, namely the content of the YouTube vegan stories in their felt forms; that is to say, the emotional, material and embodied narratives of acquiring ethical beliefs. These affective 
narratives can be arrived at through an epiphany that makes a break with what has been previously believed (that it is acceptable to eat animals) and places the vegan in a new state of rational belief that is developed further as a felt and embodied belief. This "break" recalls the work of Joel Robbins (2007) who has consistently argued that conversion to Christianity represents a significant "rupture" of both time and belief, when new adherents must put aside aspects of their old lives for something new. Like many anthropologists, Joel Robbins (2019, p. 218) describes religious conversion in terms of rupture, signifying both a break from the past and a movement towards the future, where "conversion is like revolution, in that both are, at least in their fuller forms, processes of change undertaken in light of a story about how such change can work". Gooren (2016) also notes that a dominant theme in the anthropology of conversion includes the consequences of conversion. Similar to religious processes of conversion, the vegans' conversions were explicitly situated in a social, relational milieux. In nine out of 15 videos in the sample, content creators describe a process of "making a connection", whereby the decision to become vegan was made on the basis of watching social media content about how meat, dairy and eggs are produced; as a consequence of these connections being made, which are themselves undertaken in light of YouTube narratives about processes of change, a break is made with the consumption of animals and ethical veganism's adherents begin a new life of quotidian social action to address their concerns about animal welfare. For example, American Reece says that she "never made the connection that I was so nice to my dog but then I eat cows [ . . . I don't agree with that now that I've opened my eyes and actually seen it".

A number of the YouTubers in the sample relate their encounters with animals, either alive or dead, as pivotal moments in "making a connection" and subsequently deciding to become vegan. US YouTuber Maria was an enthusiastic consumer of pork until she was given a "mini-pig" as a present. Having made an instant bond with a new pet, Maria ceased to eat pork; in turn, she came to realise that her disgust at the idea of eating her pet can be extrapolated to other animals. She notes that all animals are "sentient beings, like your dog and your cat". Reece, meanwhile, was keen to catch a fish on a family fishing trip, but once she reeled it in, she realised she killed the fish. She says: "I was like crying for a really long time after that, because that was the first time I'd made a connection." For Canadian YouTuber Mila, getting a dog at the age of 16 was the moment when she experienced "a real kind of connection with an animal [ . . ] real love for another species". Rebecca, from the UK, relates a story that she considers "weird and a little bit spiritual". In the early days of becoming vegan, when still eating meat, she says she came into contact with animals in distress that had been injured, for example by a car. These incidents are interpreted as signs by Rebecca and, for her, form a connection that links her consumption of certain animals with the suffering of all animals. "I wanted these animals to be alive," she says in her video. "It made me sad to think of them hurt, and yet the day before I had just gone and effectively paid somebody to slit an animal's throat." She follows the telling of this story by reading an extract from Jonathan Safran Foer's Eating Animals, which serves to complement her experience of seeing animals in distress with Safran Foer's graphic account of how pigs are cruelly abused at the facility of one of the largest pork producers in the US. "I read stuff I didn't like," says Rebecca. "I read stuff that made me angry, that made me sad to be a human, I cried, and then I thought no. I'm going to do this. I'm going to go vegan." While Eating Animals has formed her rational belief, her felt belief is formed by making connections between her meat consumption and the animals she has seen in distress in her neighbourhood; thus, she takes the decision to live by her ethical beliefs.

There are similar examples of the felt, embodied acquisition of ethical belief in other videos in the sample, which are related as transformative conversion-moments by content creators telling their vegan stories. YouTubers Tonia and Agnes both recount affective moments of transformation when their respective acts of eating meat serve as vivid experiences of connection to animal suffering. Tonia describes buying a rotisserie chicken and "all of a sudden" realising that her purchase had been alive previously; consequently, she 
says it made her sad and she realised she did not want to eat it. Similarly, Agnes was about to eat a chicken burger after a night out when she started "crying hysterically":

"I think this was the first time since I was a little girl that I thought about the animals as sentient beings and not as products or objects, and I felt just this overwhelming emotional connection to the animals that were completely unrecognisable in my burger. And I felt such an overwhelming injustice, because I just felt, well, who chooses who lives and who dies?"

As well as connections being made through relationships with animals, YouTubers also relate how they formed their ethical beliefs in the context of their relationships with friends, family and with wider society. Beliefs about veganism are formed within the normative behaviour of eating meat and YouTubers discuss how these norms are negotiated as they further develop their ethical beliefs. In the case of Alice, a tension emerges between the information about veganism she is acquiring on YouTube and the normative behaviour of her meat-eating family members. There appeared for her to be contradictions that could only be resolved for her by making a break with the past. She rhetorically asks in the video: why would the people she respects, with whom she has a relationship, persist in eating meat?

"I don't understand how, if this is wrong, is what the people in videos are saying about animal agriculture and the meat and dairy industries, and all of these things, if they're saying this stuff is cruel and unhealthy for you, and all of these things, then why is everybody around me eating it?"

US content creator Danny Torres, who asked for his real name to be used in the research, produces a YouTube channel about his love of skateboarding, as well as the experience of being a vegan skateboarder. His own vegan story video relates his determination to become vegan and reject masculinist prejudices about a plant-based diet:

"I was never like a total bro about anything [ . . . ] I get a lot of backlash from a lot of dudes, like saying oh man, you're so gay cause you don't eat meat. For one I think that's completely homophobic and so stupid [ ... ] It's definitely the most annoying thing about the society, that once you do something different you're labelled as a weirdo, gay, a fag, I hate that, I hate when people use those terms to describe people who are doing something different."

\subsection{Performative Belief}

With connections made and media information about veganism used to form beliefs about the rights and wrongs of eating animals, YouTubers show how ethical beliefs are created through social action, whether through the videos that they watch or in their offline interactions with friends and family. Armed with the information that they have acquired, they harness their ethical belief to create social action. For example, Joseph and Emily watched Gary Yourofsky's The Best Speech You Will Ever Hear on YouTube and recount how crying towards the end of watching A Diet for a New America had turned them vegetarian, with Yourofsky's one-hour speech turning them vegan. "He connected the remaining dots for us," says Joseph. The couple describe how they sent an email "to every contact" of theirs, requesting that they also watch the video; even knowing that "it was not going to be received so well by a number of people", the couple believed they had a "moral obligation to share the information we had just come across". In setting normative meat-eating behaviours against what she believes to be right and "the truth", Emily adds:

"Because until you know the truth, you're not actually making any decisions. Choosing one thing over another. You're just doing what you've been indoctrinated into doing from the day you were born, all our institutions in society. So you don't make a choice until you've got all the information. And then you can choose. The cruelty or the compassion. It's as simple as that."

American YouTuber Maria also conveys a sense of obligation to share the message of ethical veganism. Noting that the "vegan story" format has been requested of her "so many times" through her social media interactions, she uses the final part of her vegan 
story video to put "tons of links in the description box [ ... ] both informational and graphic, because sometimes you gotta see that stuff, sometimes you gotta realise what's really going on". For Sara in the US, her transformation to veganism happened after she had started a cooking channel on YouTube; feeling that it was a process that she needed to acknowledge, she decided to film what she calls a "vegan coming-out video", whereby she performatively transmits her ethical beliefs in order to create social action. In these instances, YouTubers are aware of how their process of becoming vegan, created through the social action of watching social media content about veganism, can be employed to create social action by making and sharing content about veganism. It is a transformative experience, both for the content creator and for their intended audience. Canadian Mila reports that she is "happy that I feel like I've been enlightened [ ... ] it's really interesting how just spreading this knowledge can really help change a person's belief system and perception". Alice credits YouTube and Instagram content about veganism as instrumental in educating people about veganism, a point echoed by Lola, who credits veganism as "the whole reason that I got into social media". This, in turn, prompts her to "inspire others to go vegan as well" through her social media content. The YouTubers in the sample also practise vegan action with friends and family outside of their social media worlds. For Maria in the US, her Instagram activity led to an invitation to Chicago from two vegan activists, after which Maria reports she "really got into speaking out" about veganism. Mila notes that going vegan has necessitated a "complete" change in lifestyle, not just in dietary terms, but in her activism as a consumer. She describes the process of "reducing the damage, learning more about what's going on, being a mindful consumer, knowing where your money is going, voting with your money [ ... ] just believing that you and a few other people can really make a difference". For Rebecca, whose mother agreed to go vegan with her at the same time as she did, veganism is an everyday commitment of "acting in a way that is more in line with how I think a person should act", while also being a "pretty giant step" to take for the environment. This is echoed by Sara's commitment to activism ("I want to change our world, I want to take care of our planet") and by Judith, who shared the documentaries she had found on YouTube with her family, after which they committed to changing their eating habits. This, reports Judith, "made me feel happy I can do something [about the environmental consequences of animal agriculture] in all this craziness".

\section{Conclusions}

The Jordi Casamitjana vs. League Against Cruel Sports tribunal of 2020, which granted legal protections to ethical vegans in British workplaces, suggests that non-religious ethical vegan beliefs deserve the status of a "protected characteristic". Our research thus far also suggests that ethical belief is a promising area of enquiry for scholars to explore the complexities of the non-religious category. Moreover, digital religion scholars are well placed to trace how these non-religious ethical beliefs are formed, transmitted and communicated by digital content creators. If religion is being subsumed under the "logic" of the media, as Hjarvard contends (Hjarvard 2008, p. 9), then there exists the scope to develop more fully how the complexity of non-religion is similarly shaped by processes of mediatisation. As shown in this article, vegans on YouTube acknowledge that their ethical beliefs are shaped significantly by what they experience through their social media activity, which prompts them to create digital content to further transmit their ethical beliefs. Vegan stories on YouTube can be seen as mediatised belief narratives, which are moulded to shape the affordances and the audiences of the YouTube platform; thus, mediatisation is an important element in how ethical beliefs are formed and subsequently remoulded into new content that communicates these belief narratives. We found that for the vloggers in our sample, research and self-education using YouTube (and, to some extent, other social media channels) is an important component of making the decision to become vegan. This is echoed by Véron in her study of French vegan blogs, who contends that blogs are "new ways of viewing and practising veganism in the twenty-first century" 
(Véron 2016, p. 289). We suggest here that digital content through social media platforms such as YouTube and Instagram afford digital religion and non-religion scholars productive ways by which to investigate how ethical belief is communicated. The small sample in this article can be developed and extended to examine other forms of ethical beliefs, such as those concerning sustainability and ethical consumption in other market sectors other than food. In particular, more research is needed to look at how processes of mediatisation affect the formation and transmission of these ethical beliefs. This may help scholars to further unpick the complexities of the non-religion category, in particular, its mediatised dimensions.

This article gives a digital religion perspective to Day's notion of anthropocentric belief, whereby belief is rooted in relationships with other people and that people believe in their relationships with other people (Day 2011, p. 156). The informants in Day's study described their beliefs not through cognitively based belief statements, but through stories "with real characters, plots and emotional content: holistic belief narratives" (Day 2011, p. 158). YouTube vegan stories are rich examples of these holistic belief narratives, which employ affect to formulate ideas of what it means to be vegan. The YouTubers in this sample freely share their ethical beliefs with their viewers, acknowledging the importance of other content creators in helping them to form - and sustain-beliefs about veganism. We use the YouTube "story time" format to illustrate how the formation of ethical belief is a mediatised process, whereby videos can be produced in response to the requests of other YouTubers, shared with the hope that the video will prompt viewers to think about their own ethical beliefs in relation to their food consumption. Thus, ethical belief is anchored in the connections that are made by watching the work of other content creators and subsequently repurposing this content to form and transmit new belief narratives. This anthropocentricity extends from relationships with other content creators to more widely encompass a connectedness to humanity, to relationships with other animals and to the future of the planet. Holdier $(2016$, p. 42) puts forward an argument for speciesistic veganism, that "if an industry does not promote human flourishing, then that industry should not be supported". The videos in this sample describe how vegan content creators reject the animal agriculture industry to instead promote narratives of human flourishing that create and sustain anthropocentric ethical beliefs. We have shown how these beliefs are acquired in the same way as the acquisition of religious beliefs, whereby individuals undergo a process of conversion as they become ethical vegans.

While noting Day's contribution concerning the performance of belief, Lövheim (2016, pp. 107-8) suggests that mediatisation is a concept that could be developed further in Day's "believing in belonging" thesis, asking what is meant by the idea of belief as performative and social in a world where many people's close relationships are mediated through digital channels. Lövheim cites YouTube as a site for such enquiry and this article responds to this suggestion, to contend that performances of living together ethically, as enacted through digital content creation, can help scholars better understand shared experience between and beyond the religious/non-religious binary. In doing so, we have treated the "vegan story" format as a performative "belief narrative" (Day 2011) to show how vegan YouTubers' ethical beliefs have been shaped significantly by the digital content of other YouTubers, based on what they consider to be the "facts" and the "truth" of what they learn about the animal agriculture industry and its consequences. Their beliefs, thus, are deeply mediatised and mould their performative social actions. The contribution of this paper has been to show that these beliefs illustrate the cogency, cohesion and importance of philosophical belief as a "substantial aspect of human life and behaviour", as defined in the 2010 Equality Act and applied in Casamitjana vs. LACS. Taking Lee's (Lee 2015, p. 194) suggestion that the non-religion category can be approached as a placeholder term to facilitate empirical work, the performative "belief narrative" offers researchers a methodology by which to develop further research to understand the beliefs and related identities of non-religious groups, which gives agency to research participants to self-define in ways that are salient and meaningful to them; moreover, it engages with the mediatised processes in which 
ethical belief is acquired and transmitted, which in turn addresses the research lacuna between non-religion literature and digital religion literature. User-generated content on YouTube is employed here to show how the processes of mediatisation have contributed to the ethical turn as it is performed on social media platforms. As the data here suggest, the ethical beliefs of YouTube vegans are not just anchored in relationships with other vegan content creators, but also in "making a connection" to animals and to the notion of shared humanity in the face of catastrophic climate change.

Author Contributions: Author Contributions: Conceptualisation, A.D. and K.H.; data curation, K.H.; writing—original draft preparation, K.H.; writing—review and editing, A.D. and K.H.; supervision, A.D. All authors have read and agreed to the published version of the manuscript.

Funding: This research received no external funding.

Conflicts of Interest: The authors declare no conflict of interest.

\section{References}

Abidin, Crystal. 2015. Communicative intimacies: Influencers and perceived interconnectedness. Ada 8: 1-16. [CrossRef]

Adams, Matthew, and Jayne Raisborough. 2010. Making a difference: Ethical consumption and the everyday. British Journal of Sociology 61: 256-74. [CrossRef] [PubMed]

Altheide, David L., and Robert P. Snow. 1979. Media Logic. Beverly Hills: Sage.

Arcy, Jacquelyn. 2016. Emotion work: Considering gender in digital labour. Feminist Media Studies 16: 365-68. [CrossRef]

Beaman, Lori. 2017. Living Well Together in a (Non)Religious Future: Contributions from the Sociology of Religion. Sociology of Religion 78: 9-32. [CrossRef]

Berryman, Rachel, and Misha Kavka. 2018. Crying on YouTube: Vlogs, self-exposure and the productivity of negative affect. Convergence: The International Journal of Research into New Media Technologies 24: 85-98. [CrossRef]

Bishop, Sophie. 2019. Managing visibility on YouTube through algorithmic gossip. New Media E Society 21: 2589-606. [CrossRef]

Blanes, Ruy Llera, and Galina Oustinova-Stjepanovic. 2015. Introduction: Godless People, Doubt, and Atheism. Social Analysis 59: 1-19. [CrossRef]

British Social Attitudes. 2019. Religion: Identity, Behaviour and Belief over Two Decades. Available online: https://www.bsa.natcen. ac.uk/latest-report/british-social-attitudes-36/religion.aspx (accessed on 21 December 2020).

Cheruvallil-Contractor, Sariya, Tristram Hooley, Nicki Moore, Kingsley Purdam, and Paul Weller. 2013. Researching the Non-Religious: Methods and Methodological Issues, Challenges and Controversies. In Social Identities between the Sacred and the Secular. Edited by Abby Day, Giselle Vincett and Christopher R. Cotter. London and New York: Routledge.

Clark, Lynn Schofield. 2011. Considering Religion and Mediatisation through a Case Study of JK's Big Day (The JK Wedding Entrance Dance): A Response to Stig Hjarvard. Culture and Religion 12: 167-84. [CrossRef]

Cotter, Christopher. 2011. Toward a Typology of 'Nonreligion': A Qualitative Analysis of Everyday Narratives of Scottish University Students. Unpublished Master's dissertation, University of Edinburgh, Edinburgh, UK.

Cotter, Kelley. 2019. Playing the visibility game: How digital influencers and algorithms negotiate influence on Instagram. New Media $\mathcal{E}$ Society 21: 895-913. [CrossRef]

Day, Abby. 2009. Researching Belief without Asking Religious Questions. Fieldwork in Religion 4: 86-104. [CrossRef]

Day, Abby. 2011. Believing in Belonging: Belief and Social Identity in the Modern World. Oxford: Oxford University Press.

Day, Abby. 2016. Believing in Belief: Toward the Secularisation of Faith in Global Economies. In Religion: Beyond Religion. Edited by Phil Zuckerman. Farmington Hills: Macmillan Reference USA.

Day, Abby. 2020. Sociology of Religion, Overview and Analysis of Contemporary Religion. London: Routledge.

Doward, Jamie. 2019. Worker Could Make History in a Crucial Case for Ethical Vegans. Available online: https://www. theguardian.com/lifeandstyle/2019/dec/29/ethical-vegan-jordi-casamitjana-protected-status-court-tribunal (accessed on 21 December 2020).

Duffy, Brooke Erin. 2016. The Romance of Work: Gender and Aspirational Labour in the Digital Culture Industries. International Journal of Cultural Studies, 19. [CrossRef]

Duffy, Brooke Erin. 2017. (Not) Getting Paid to Do What You Love. New Haven: Yale University Press.

Engelke, Matthew. 2010. Religion and the Media Turn: A Review Essay. American Ethnologist 37: 371-79. [CrossRef]

Gooren, Henri. 2016. Religious Conversion. Available online: https://www.oxfordbibliographies.com/view/document/obo-97801997 66567/obo-9780199766567-0146.xml?rskey=rIIp6f\&result=1\&q=gooren\#firstMatch (accessed on 21 December 2020). [CrossRef]

Greenebaum, Jessica Beth. 2016. Questioning the Concept of Vegan Privilege: A Commentary. Humanity \& Society 41: 355-72. [CrossRef]

Guenther, Katja M. 2009. The politics of names: Rethinking the methodological and ethical significance of naming people, organisations and places. Qualitative Research 9: 411-21. [CrossRef] 
Hepp, Andreas, Stig Hjarvard, and Knut Lundby. 2015. Mediatisation: Theorising the Interplay between Media, Culture and Society. Media, Culture E Society 37: 314-24. [CrossRef]

Hjarvard, Stig, and Mia Lövheim. 2012. Mediatization and Religion: Nordic Perspectives. Göteborg: Nordicom.

Hjarvard, Stig. 2008. The Mediatisation of Religion: A Theory of the Media as Agents of Religious Change. Northern Lights: Film $\mathcal{E}$ Media Studies Yearbook 6: 9-26.

Hochschild, Arlie Russell. 2012. The Managed Heart: Commercialisation of Human Feeling. Berkeley: University of California Press. First published 1983.

Holdier, A. G. 2016. Speciesistic Veganism: An Anthropocentric Argument. In Critical Perspectives on Veganism. The Palgrave Macmillan Animal Ethics Series; Cham: Springer International Publishing AG.

Ingold, Tim. 2013. Anthropology Beyond Humanity. Suomen Antropologi: Journal of the Finnish Anthropological Society 38: 5-23.

League Against Cruel Sports. 2020. League Statement Regarding Jordi Casamitjana. Available online: https://www.league.org.uk/ league-statement-jordi-casamitjana (accessed on 21 December 2020).

Lee, Lois. 2012. Research Note: Talking about a Revolution: Terminology for the New Field of Non-religion Studies. Journal of Contemporary Religion 27: 129-39. [CrossRef]

Lee, Lois. 2015. Recognising the Non-religious: Reimagining the Secular. Oxford: Oxford University Press.

Legewie, Nicolas, and Anne Nassauer. 2018. YouTube, Google, Facebook: 21st Century Online Video Research and Research Ethics. Forum: Qualitative Social Research, 19. [CrossRef]

Legislation.gov.uk. 2010. Equality Act 2010 Explanatory Notes. Available online: https://www.legislation.gov.uk/ukpga/2010/15/ section/10/notes?view=plain (accessed on 21 December 2020).

Lewis, Tania, and Alison Huber. 2015. A Revolution in an Eggcup? Supermarket Wars, Celebrity Chefs and Ethical Consumption. Food, Culture \& Society 18: 289-307. [CrossRef]

Lövheim, Mia, and Evelina Lundmark. 2019. Gender, Religion and Authority in Digital Media. Essachess 12: 23-38.

Lövheim, Mia. 2016. Around Abby Day's Believing in Belonging: Belief and Social Identity in the Modern World. Religion and Society 7: 97-111. [CrossRef]

Manyukhina, Yana. 2017. Consumer Food Ethics: Considerations of Vulnerability, Suffering and Harm. Journal of Agricultural and Environmental Ethics 30: 595-614. [CrossRef]

Markham, Annette. 2012. Fabrication as ethical practice: Qualitative inquiry in ambiguous internet contexts. Information, Communication $\mathcal{E}$ Society 15: 334-53. [CrossRef]

Patterson, Ashley N. 2018. YouTube Generated Video Clips as Qualitative Research Data: One Researcher's Reflections on the Process. Qualitative Inquiry 24: 759-67. [CrossRef]

Portwood-Stacer, Laura. 2012. Anti-consumption as tactical resistance: Anarchists, subculture, and activist strategy. Journal of Consumer Culture 12: 87-105. [CrossRef]

Robbins, Joel. 2007. Continuity thinking and the problem of Christian culture. Current Anthropology 48: 5-17. [CrossRef]

Robbins, Joel. 2019. Afterword: Some Reflections on Rupture. In Ruptures: Anthropologies of Discontinuity in Times of Turmoil. Edited by Martin Holbraad, Bruce Kapferer and Julia F. Sauma. London: UCL Press, pp. 218-32. [CrossRef]

Salonen, Anna Sofia. 2018. Living and dealing with food in an affluent society-A case for the study of lived (non)religion. Religions 9: 306. [CrossRef]

Smithers, Rebecca. 2020. Tesco Sets 300\% Sales Target for Plant-Based Alternatives to Meat. Available online: https://www. theguardian.com/business/2020/sep/29/tesco-sets-300-per-cent-sales-target-for-plant-based-alternatives-to-meat (accessed on 21 December 2020).

The Vegan Society. 2020. Veganism in the UK. Available online: https://www.vegansociety.com/news/media/statistics\# vegandietintheuk (accessed on 21 December 2020).

Trzebiatowska, Marta. 2018. Sovereign of Herself: Women's Narratives of 'Lived Atheism'. Secularism and Nonreligion, 7. [CrossRef]

Véron, Ophélie. 2016. From Seitan Bourguignon to Tofu Blanquette: Popularising Veganism in France with Food Blogs. In Critical Perspectives on Veganism. The Palgrave Macmillan Animal Ethics Series; Cham: Springer International Publishing AG.

Woodhead, Linda. 2016. Intensified Religious Pluralism and De-differentiation: The British Example. Society 53: 41-46. [CrossRef] 